\title{
GÊNERO E POLÍTICA NO BRASIL E NA ALEMANHA ${ }^{1}$ \\ Entrevista com Dinah Leschzyk
}

\author{
Gender and politics in Brazil and Germany
}

\author{
Dinah Leschzyk ${ }^{2}$ \\ Justus-Liebig-Universität Gießen
}

\begin{abstract}
RESUMO: Nesta entrevista, a analista de discurso Dinah Leschzyk apresenta um panorama de suas pesquisas sobre o discurso político na América Latina. Ela inicia tratando das especificidades da campanha política na Colômbia, sobre a qual desenvolveu sua tese de doutorado, e nos apresenta sua pesquisa mais recente, relativa ao impacto do gênero na política. Ela tem realizado análises comparativas de discursos que circulam na mídia e nas campanhas eleitorais sobre as duas mulheres presidentes, Angela Merkel e Dilma Rousseff, assim como sobre os discursos de ódio proferidos contra a comunidade LGBT pelas extremasdireitas alemã e brasileira.

Palavras-chave: Análise do discurso; Política; América Latina; Gênero; Brasil e
\end{abstract} Alemanha.

\begin{abstract}
In this interview, a discourse analyst Dinah Leschzyk presents an overview of her research on political discourse in Latin America. She began to address the specifics of the political campaign in Colombia, and presents her most recent research, regarding the impact on gender in politics. By comparative analyzes of discourses in the electoral campaigns about the presidents, Angela Merkel and Dilma Rousseff, as well as about the hate speeches given against the LGBT community by the extreme right in Brazil and Germany.

Keywords: Discourse analysis; Politics; Latin America; Gender; Brazil and Germany.
\end{abstract}

\footnotetext{
${ }^{1}$ Entrevista realizada no dia 12 de setembro de 2018, durante o V CIAD - Colóquio Internacional de Análise do Discurso: Discurso e (pós)verdade. Efeitos de real e sentidos da convicção. Na ocasião, a entrevistada, além de participar do evento, proferiu dois cursos junto ao Programa de Pós-graduação em Linguística da Universidade Federal de São Carlos (PPGL-UFSCar): "A representação da igualdade, justiça e democracia nas campanhas eleitorais colombianas de 2010: uma análise crítica do discurso"; e "Política e gênero? Discursos Anti-LGBTI no Brasil e na Alemanha". A equipe responsável pela produção, transcrição, retextualização e revisão desta entrevista foi composta por Bianca B. Rapelli de Moraes, Gustavo Diniz, Johann Faigle do Nascimento, Nadia S. do Nascimento, Raoni D. B. Gomes, Gustavo Dias, Guilherme Gennari, Caio Heitor de S. Camargo, discentes do curso de Bacharelado em Linguística, e Luzmara Curcino, docente no Departamento de Letras e no Programa de Pós-graduação em Linguística da UFSCar. A entrevista contou com o apoio técnico de Daniel P. Graciano, Lívia Damaceno e Caio Carniel, discentes do Programa de Pós-graduação em Linguística.

${ }^{2}$ Professora no Institut für Romanistik - Justus-Liebig-Universität Gießen, na cidade de Gießen na Alemanha. Formada em Filosofia, especialista em Análise Crítica do Discurso político. Dedica-se ao discurso político na América Latina e realiza pesquisa comparativa quanto ao impacto do gênero nas eleições de Angela Merkel e Dilma Rousseff.
} 


\section{Discurso Político e América Latina}

Entrevistadores: Em suas pesquisas, você tem se dedicado à análise de discursos políticos, em especial, dos pronunciamentos de campanha de políticos de países da América Latina. Quando e por que se interessou por este tema? Em relação ao Brasil, desde quando tem se interessado pelo o que ocorre politicamente aqui?

Dinah Leschzyk: Iniciei meus estudos superiores em 2001, dedicando-me ao aprendizado do espanhol, do italiano e, por estranho que pareça, de administração de empresas. Esta última formação eu de fato não dei prosseguimento. Já em relação ao estudo de línguas românicas, e depois de aspectos da cultura das sociedades de uso dessas línguas, eu me identifiquei bastante. Por essa razão, eu me interessei cada vez mais pela cultura e pela política latinoamericana, o que então se tornou meu tema de pesquisa. Em relação ao Brasil, meu interesse se deu apenas em 2010, quando então pude iniciar meus estudos da língua portuguesa falada no Brasil. Isso se deu quando iniciei minha atuação docente no Instituto de Romanística na Universidade de Giessen, para atuar com o ensino de espanhol e de italiano. No entanto, nesse período, a oferta de cursos de italiano foi suspensa. O Departamento de Italiano foi extinto pela escassez de verba. Então, passei a trabalhar com as disciplinas relativas a língua e cultura espanhola, sobretudo da América Latina. Foi nessa ocasião que pude iniciar meus estudos de português, língua que eu não dominava e que também não fazia parte do quadro de disciplinas desta universidade alemã onde eu atuava, mas que viria muito em breve se fortalecer em função do interesse crescente da Alemanha e dos alemães pelo Brasil, pela língua, cultura e política deste país.

À época, eu concentrei minha atenção nas eleições presidenciais de 2010 na Colômbia, o que se tornou o tema de minha pesquisa de doutorado. Por essa razão, não pude, nessa ocasião, realizar um curso sistemático de português. Minha tese, sustentada teoricamente pela Análise Crítica do discurso ${ }^{3}$, consistiu em analisar o discurso político partidário e eleitoral proferido nas campanhas dos candidatos à presidência da Colômbia. Por essa razão, tive de retardar um pouco o meu aprendizado sistemático do português brasileiro. Apenas após a defesa de minha tese de doutorado, finalizada em 2015 e defendida em abril de 2016, pude estabelecer como tema de pesquisa a política no cenário brasileiro, em especial porque me interessei em analisar o que se enunciava sobre o governo de Dilma Rousseff, a primeira

\footnotetext{
${ }^{3}$ Cf. Fairclough (1989; 2001).
} 
mulher a governar o Brasil, assim como ocorrera na Alemanha com Angela Merkel. Meu primeiro interesse de pesquisa recaiu sobre decisões de âmbito linguístico, de política linguística, tomadas por seu governo. Hoje, no Brasil, é possível ter, por exemplo, os diplomas oficiais com os títulos outorgados no feminino, e não somente padronizados no masculino como antes. Essa foi uma das mudanças empreendidas em seu governo, com valor simbólico importante. Ela também tomou uma série de outras medidas nesse âmbito ${ }^{4}$, e foi durante seu governo que se deu a emergência da "Primavera das mulheres", temas sobre os quais direcionei então meu interesse de pesquisa.

De início, escrevi um artigo a esse respeito para uma apresentação em um evento intitulado "Lusitanistentag", em alemão, dedicado aos estudos e aos estudiosos lusitanistas, que se ocupam da língua e da cultura portuguesa. Desde então, comecei a trabalhar com discursos de gênero a respeito das pessoas LGBT, com o que se dizia a seu respeito na mídia, na política. Primeiro, analisei o discurso adotado pelo partido alemão "Alternativa para a Alemanha" a esse respeito. É impressionante a coincidência entre o que os membros desse partido de extrema-direita alemão, recém-criado, enunciam e o discurso de Bolsonaro e seus equivalentes no Brasil. Diante das regularidades e similitudes dos discursos de ódio dirigidos às minorias, da semelhança de suas proposições e pontos de vista, eu então direcionei minhas pesquisas para a política brasileira, e decidi estudar comparativamente seus discursos.

O Brasil, hoje, é o país mais em foco entre os pesquisadores de meu Departamento de Linguística. Além do interesse pelo país, a maioria dos professores de português e de português brasileiro vêm do Brasil. Esse contexto de trabalho, a conjuntura política internacional e meu interesse pessoal pela língua e cultura do Brasil foram decisivos para o redirecionamento de minhas pesquisas.

\footnotetext{
${ }^{4}$ Em seu mandato, foi a presidente que mais nomeou mulheres como ministras, visando atingir a paridade de gênero; houve ainda expansão do acesso, sobretudo a mulheres negras, aos programas sociais do governo; elas também se tornaram as titulares dos benefícios; houve a aprovação da PEC das empregadas domésticas, que ampliou direitos formais dessas categorias; foi sancionada a lei do feminicídio tornando-o crime hediondo, entre outras ações.

5 "Primavera das mulheres" consistiu em uma série de eventos públicos, ocorridos em 2015, grande parte deles sob a forma de manifestações na rua, como parte da luta das mulheres por reconhecimento de seus direitos como cidadãs e contra o machismo estrutural.

${ }^{6}$ Partido alemão de extrema-direita, fundado em 2013. Segmentos do partido possuem tendências racistas, antissemitas, islamofóbicas e xenofóbicas, associadas a movimentos ligados ao neonazismo e identitarismo.
} 


\section{Brasil e Alemanha: política e gênero}

Entrevistadores: Tanto o Brasil como a Alemanha elegeram mulheres como presidentas. A seu ver, o gênero desempenha algum papel no exercício de cargos políticos?

Dinah Leschzyk: Em geral, quando uma mulher ocupa um cargo político, questões de gênero emergem como tema. Se um homem ocupa o mesmo cargo, o mesmo não ocorre. Nesse caso, isso não se torna um tema porque não seria algo de interesse ou relevante. No caso das mulheres que atuam em cargos políticos, em especial aqueles de grande visibilidade, elas são algo de comentários com diferentes graus de sexismo. Por exemplo, a roupa que ela usa se torna um tema, a sua maquiagem, a sua beleza, os seus gestos e movimentos julgados quanto a sua maior ou menor feminilidade etc. Em geral, a aparência da mulher torna-se um tema, e um tema que ocupa um grande espaço. No caso dos homens, não. Normalmente não se comenta os sapatos que um homem escolheu usar na cerimônia de posse ou usa na sua rotina de trabalho. A cobertura da atuação política, pela mídia, se ocupa muito mais da vida privada das mulheres: se elas têm filhos, se são casadas... Enfim, tudo isso é mais tematizado do que à respeito de suas ideias políticas. Sua aparência sobressai ao invés de sua competência política, formação, capacidade e habilidades. No caso de Angela Merkel, na Alemanha, falou-se muito do fato de que, no caso dela, a questão de gênero não foi tão explorada, nem desempenhou um papel importante, e isso porque ela não explorava aspectos da feminilidade, já que sempre usou roupa discreta e decente, como se ao dizer isso não houvesse de antemão um julgamento típico desses que se direcionam exclusivamente a mulheres que trabalham fora ou exercem cargos públicos. Isso é dito, como se houvesse nisso um tipo de neutralidade a respeito do tema do gênero. O mesmo me parece ter ocorrido com Dilma Rousseff no Brasil.

\section{Brasil e Alemanha: seus paralelos políticos sobre a questão LGBT}

Entrevistadores: Parece existir no atual momento, em diferentes países, um refluxo das ideias progressistas, de modo que têm crescido o volume de ideias, de partidos e de representantes da extrema-direita. Há paralelo entre a extrema-direita da Alemanha e do Brasil, no que consiste ao tema LGBT? 
Dinah Leschzyk: Há muitos paralelos, muito mais do que eu pensava. Antes do estudo que estou realizando no momento, eu não imaginei que pudessem ser tantos, pois o Brasil e a Alemanha são países bem diferentes quando se considera a sua história, a sua situação política atual, o modo de viver de ambas as sociedades. Eu não esperava que as semelhanças fossem tantas, como agora vejo que são. Por exemplo, o vocabulário empregado por esses grupos de extrema-direita é muito similar. A expressão "ideologia de gênero", da qual muito se fala hoje em dia, no Brasil, também é empregada com as mesmas finalidades denunciativas na Alemanha. Ela se tornou uma expressão do vocabulário anti-LGBT e é sempre evocada em nome da moral e sob a forma de um simulacro: por um lado, é entendida de forma negativa porque a referência ao termo "ideologia", tal como exploram esses grupos atualmente, é algo considerado exclusivamente ruim e exclusivamente de esquerda (e se é de esquerda é ruim porque ideológico, se é ideológico é ruim porque de esquerda); por outro lado, porque se entende que o "gênero", como tema tabu e polêmico, se refere apenas à sexualidade de grupos minoritários estigmatizados de longa data e vítimas de preconceito por membros de grupos majoritários, que se veem sob o risco de perder suas prerrogativas, entre elas a do direito de serem preconceituosos sem que isso se volte contra eles, tendem a "denunciar" de forma incisiva e derrisória toda e qualquer mudança que possa se contrapor a sua forma de ver o mundo.

Tanto no Brasil quanto na Alemanha, um outro ponto em comum da retórica da extrema-direita é dizer que se opõe ao 'politicamente correto', argumentando que isso é como se fosse um tipo de censura que se lhes foi imposto. Esse é mais um dos simulacros que evocam normalmente em seu discurso anti-LGBT, segundo o qual são eles que são vítimas de uma polícia do que pode ou não ser dito. Os membros da extrema-direita também se referem a questões ligadas ao ensino nas escolas. Aqui no Brasil, diante do projeto 'Escola sem homofobia' ${ }^{7}$, assim como na Alemanha com projetos similares, a extrema-direita se posicionou de forma muito intensa e mentirosa, ao alegar que não seria papel da escola tratar de temas como diversidade sexual e diversidade de gênero, e ao levantar calúnias dizendo que o objetivo do projeto era o de autorizar ou fomentar entre as crianças e jovens das escolas a mudança de sua orientação sexual. Eles difundiram, por diversos meios, a falsa ideia de que

\footnotetext{
${ }^{7}$ Este projeto fez parte do "Programa Brasil contra a Homofobia", do Ministério da Educação e do Ministério de Direitos Humanos, em parceria com a UNESCO, e teve por objetivo combater o preconceito e a violência de gênero nas escolas. Lançado durante o governo Lula, pelo então ministro da educação Fernando Haddad, o projeto foi imediata e duramente criticado por parte da oposição, em particular a extrema-direita emergente, que pejorativamente se referia ao material didático produzido para a realização do projeto como "kit gay". O primeiro a empregar essa expressão foi justamente o então deputado do Centrão Jair Bolsonaro.
} 
através da informação sobre questões ligadas à diversidade sexual havia antes um projeto de estímulo à sexualidade precoce e distorcida do ponto de vista dos valores da família.

Outro exemplo bastante banal da semelhança do que enunciam esses grupos nesses dois países, e que foi motivo de polêmica na Alemanha, e com certeza também aqui no Brasil, foi aquele relativo à criação de banheiros unissex, na escola e em repartições públicas. Normalmente, o que poderia haver de grave nisso a ponto de uma pessoa se manifestar contra um banheiro? Não acho que seja algo que deveria mobilizar as pessoas, que deveria levá-las às ruas em passeatas com cartazes como "Não queremos um banheiro unissex". No entanto, isso aconteceu. Este se tornou um tema mobilizador, uma vez que a direita fez dele uma constante e sempre como se isso fosse algo muito negativo e destrutivo para a sociedade.

Outro desses temas comuns, com maior repercussão no Brasil do que na Alemanha, é o da denúncia de que a comunidade LGBT recebe muita atenção e recursos do Estado, de que tem privilégios. Um dos exemplos que citam é o do apoio do Estado à 'Parada do Orgulho LGBT' de São Paulo. O então deputado e depois candidato à presidência, Jair Bolsonaro, recorreu a esse tema diversas vezes como plataforma política.

Um argumento usado frequentemente na Alemanha é o de que lá não existe discriminação de pessoas LGBT, e assim sendo não é necessário falar em discriminação, criar projetos, financiar atividades, porque, segundo eles, os problemas apontados pela comunidade LGBT sequer existem. Não ouvi tanto esse tipo de afirmação no Brasil, mas pode ser que também usem esse argumento aqui. Para resumir e concluir, acredito que há muitos paralelos na retórica utilizada e na escolha dos tópicos que são trazidos à tona pela extrema-direita alemã e brasileira em relação às pessoas LGBT. Essa semelhança não me parece mera coincidência. Ela resulta de um jogo de forças político, transnacional, que se organiza de modo muito eficiente. Este é o cenário sobre o qual precisamos cada vez mais refletir e nos posicionar a respeito.

\section{Referências}

FAIRCLOUGH, Norman. Language and power. New York: Longman, 1989.

FAIRCLOUGH, Norman. Discurso e mudança social. Brasília: Editora da UnB, 2001.

Recebido em: 12 de fevereiro de 2020.

Aceito em: 17 de abril de 2020. 